\title{
The reasons for Red Data Books
}

\author{
N. J. Collar
}

The late Sir Peter Scott, a former President of Fauna and Flora International, proposed the idea of Red Data Books as conservation tools more than 30 years ago. Today, the international Red Data Book programme appears to be effectively at an end, with priority being given to Action Plans and Conservation Assessment Management Plans for groups of taxa. These, however, cannot entirely replace Red Data Books, and the author of this paper argues that Red Data Books have many vital roles to play in species conservation and makes a plea for their renascence.

\section{Red Data Books: evolution and endangerment}

International Red Data Books were conceived by Peter Scott in 1963 as 'a register of threatened wildlife that includes definitions of degrees of threat' (Scott et al., 1987). Originally published and paid for by the IUCN under the auspices of its Survival Service (now Species Survival) Commission (SSC), they began appearing as early as 1964 and, for the first 15 years of their existence, were issued as looseleaf, ring-bound volumes: the idea was to keep them in a permanently modern condition by adding texts ('sheets') on newly evaluated taxa at regular intervals, and by replacing older ones with updated accounts.

Much of this work was undertaken by authors dispersed around the earth, operating without the benefit of each others' experience or contacts, but in 1980 the IUCN sought to rationalize the situation by establishing a Red Data Book unit outposted from its own headquarters in a 'centre of excellence' (essential for library resources and as a crossroads for specialists in wildlife conservation); it chose Cambridge, UK. With this phase and the emergence of word-processing, the unwieldy ring-binder concept was overtaken by the true book, which meant that accounts of threatened taxa became updatable in the electronic system that was then being developed for their storage, and therefore tended no longer to be confined to one or two sheets.
Since the creation of the IUCN's Conservation Monitoring Centre in Cambridge (now the World Conservation Monitoring Centre, funded equally by the IUCN, WWF and UNEP), nine volumes of the international Red Data Book have appeared, treating 1233 taxa over 13 years (1980-92) at an average of 95 taxa per year (Table 1). Three of these volumes - the two in 1982 and the 1985 bird tome were described as 'part 1 ' of a global review of the class in question, but only one has been followed by a part 2 (the 1992 bird book). A volume on North American and Mexican fish was completed but not published in the mid1980s, and plants received no attention (a volume having appeared in 1978) beyond a geopolitical directory in 1986 .

Despite three books in the first 3 years of the present decade, and burgeoning world-wide interest in 'red listing' at the national level, the international Red Data Book programme is effectively, if unofficially, at an end; indeed, as a coherent endeavour, it has been over since the late 1980s. While it was always clear that certain groups - plants, invertebrates, fish - were too incompletely known and too speciose ever to be treated exhaustively, the original expectation, as suggested by the use of 'part 1 ' for books up to 1985, was to address the three classes of higher vertebrate as consistently and comprehensively as possible. Nevertheless, the recent mammal volumes are not subtitled as later parts of the edition launched in 1982; and, however excellent in themselves, they 
Table 1. International Red Data Books published since the establishment of the (World) Conservation Monitoring Centre in $1980^{*}$

\begin{tabular}{lccc}
\hline Subject & Year & No. pages & No. taxa \\
\hline South American and Australian mammals & 1982 & 516 & 145 \\
Turtles, crocodiles and tuatara & 1982 & 426 & 83 \\
Invertebrates (global sample) & 1983 & 632 & 254 \\
African birds & 1985 & 796 & 177 \\
Swallowtail butterflies & 1985 & 401 & 78 \\
African primates & 1988 & 155 & 44 \\
Malagasy lemurs & 1990 & 240 & 46 \\
Cetaceans & 1991 & 429 & 79 \\
New World birds & 1992 & 1150 & 327 \\
\hline
\end{tabular}

* This table does not include the Smithsonian Press's paperback reissue in 1981, under the title Endangered Birds of the World, of the ringbound 1978-79 bird volume. In the final column, in cases where all subspecies of a species are treated (primates/lemurs), the species itself has not been counted in the total.

reflect a trend towards narrow, compartmentalized analysis, and towards contract work by outposted authors, thereby converging on the IUCN Action Plans that have now fully supplanted them. Apart from the birds, whose two continental volumes to date - a third, on Asia, is in preparation - have been supplemented and updated by an annotated list of the world's threatened bird species under the title Birds to Watch $(1988,1994)$, all that now remains of the original programme is the IUCN Red List of Threatened Animals (1986, 1988, 1990, 1993).

\section{Scarcity (money) and plenty (species): the inescapable cycle}

Costs inevitably figure as the primary cause in the demise of the programme; but since the late 1970 s the entire practice of single-species conservation, with which Red Data Books are naturally associated, had been increasingly called into question, partly for want of funds even for existing projects, partly from mounting frustration at the sheer multiplicity of species needing and not receiving attention, and partly from the sense that undivided attention had now to be given to major ecosystem preservation. For a time, the concept of triage - the conscious decision and open declaration not to intervene in apparently irre- mediable cases - was floated in an attempt to cope rationally with the situation (see, for example, Lovejoy, 1976; Myers, 1979). However, because no organization could ever actually admit to establishing what might be described as 'priorities for extinction', the idea never flourished.

In its place emerged the concept of 'conservation for development' (this was, for example, the underlying theme of the 1982 World Parks Congress), whose roots lay in the World Conservation Strategy of 1980, and whose solution to the problem - the multiplicity of unfunded threatened species - was, at least as I saw it, to assume its abiding irrelevance. This concept framed the international conservation movement in Darwinian terms of adapt-or-die, with adaptation entailing the close alignment of its interests with those of the agencies of global development. For this school of thought the apparent sheer inutility and even obstructiveness of threatened species (if these things were actually noticed at all) was always going to make at least their documentation - which clearly has costs that cannot always be seen to repay themselves - a target of unspoken triage. Certainly by the mid-1980s the IUCN's Red Data Book programme was already deep in trouble.

Nevertheless, if the championing of threatened species (not of course solely the remit of Red Data Books) became an uneconomic 
proposition, the championing of economic primacy remained, for conservation, an unsustainable paradox. By the end of the decade, a reconciliation between the two camps became viable with the emergence of a concept with the potential simultaneously to rescue and to erase the issue of threatened species, rather in the way genetic swamping by one species can be thought both to assist another (through new vitality) and to destroy it (through lost identity). In this case it was generic swamping, and the hero and culprit was of course 'biodiversity', whose enduring attraction lies in its user-friendly plasticity of interpretation (all things to all men) and in the solid neutrality of its constituency (all things alive). It includes threatened species; but it also conveniently subsumes them.

Biodiversity is thus not to be disparaged as an ephemeral buzzword: it has established what is effectively a two-way lifeline between conservation and development that was never there when these two notions were linked by the word for. Despite a putative loss of focus and urgency over particular cases, the general issue is now being taken with a revitalized and long overdue seriousness. The debate has moved up to a less emotional, more rational stratum, important new ground where the conservation community can encounter on more nearly equal terms the governments, international agencies and private corporations that hold such sway over the future of the planet.

All the same, biodiversity is by definition indefinite, which renders it permanently open to misinterpretation on a grand scale and to abuse by political bandwaggoners. All life on earth may be portrayed as an irrefutable cause and an indissoluble inheritance, but it also remains an inconceivable complexity. In this regard, a striking feature of the Rio summit of June 1992 was the conceptual shorthand in which both politicians and media referred to the then embryonic Biodiversity Treaty as a treaty for threatened species. The irony of this lay less in the fact that threatened species were ostensibly what 'biodiversity' was seeking to escape from, than in the inescapable fact that they are what it leads back to: for if we seriously want to keep all life on earth, then we have to know which components of it we are to lose most immediately and which others we can safely allow to take care of themselves. However important it is for conservation to develop information systems to new capacities (and it clearly is), an inevitable consequence of a true commitment to biodiversity is none other than a commitment to the conservation of threatened species. We come full circle.

\section{Phoenix: the reasons for revival}

Such a commitment predicates a Red Data Book programme, because the best preventative of extinction requires not merely the identification of those forms at risk but also the systematic review, analysis and publication of all the data relevant to their conservation. Indeed, identification without the supporting data remains wide open to charges of arbitrariness, assumption and favouritism, and the plain fact is that in the absence of such data it is in most cases impossible to make a confident, clear and credible assessment of a species's status. It might of course be argued that the important thing is the gathering and disseminating of the data needed to carry out appropriate actions to save species, and that Red Data Books are not necessarily the most appropriate medium for this. However, there are numerous considerations - ethical, economical, educational, practical and institutional - that make the case for a revived programme compelling.

In outlining them here, my use of such concepts as truth, objectivity, neutrality and democracy is not an attempt at special pleading under the guise of a quaint noble idealism, rather it is to insist that such idealism is the commonplace spring of any real service to human development. I accept that all these things are relative. I acknowledge having made the consistent assumptions that species are the principal unit of concern in this matter and that 'priorities' are to be determined, in the first place, on the simple basis of proximity to global extinction. 


\section{(1) Priority-setting}

(a) Red Data Books help save species from extinction. This is the primary reason for their existence. They achieve this goal by concentrating minds on true priorities - the most precariously placed species on the planet - and by stimulating and guiding work on these priorities: they establish the basis for intervention and the right courses of action. They also achieve it by doing all the other things itemized below.

(b) They shape public policy. Bean (1987) acknowledged the importance of their support for legal instruments relating to trade, habitat protection, reserve establishment and environmental impact assessment. Scott et al. (1987) noted how much the data published in Red Data Books influences listings in legislation', and C. de Klemm likewise observed (in Fitter and Fitter 1987: 57) that 'Red Data Books... are important because legislators need precise and accurate information'. As an example, it was the draft material for Threatened Birds of the Americas that was used to develop the official Brazilian list (Bernardes et al., 1992).

(c) They identify key habitats, key issues and key sites. Red Data Books show where, why and how species are dying out, and thus give shape and force to initiatives aimed at eliminating harmful activities and practices, whether local, national or international. The full documentation of individual ranges has made it possible to determine key sites of sympatric occurrence for many different species of bird (for example Wege and Long, 1995) and can do the same for key habitats (for example Long, 1995). Similar exercises are clearly possible for other life-forms; and synthesizing work (in which site-based analyses of birds, mammals, reptiles and certain butterflies and plants are merged) would then offer the most focused, economical and practical guides to the preservation of biodiversity on the planet (Collar, 1994), complementing initiatives to identify more general distributions of species through biome and ecosystem reviews. (d) They help target funds and reduce costs. The determination of true priorities is a service in both economic and ethical terms. Mistaken priorities and duplicated effort are common in conservation; Red Data Books, properly researched, provide a strong antidote. They serve to 'demythologize' species (because assumptions and guesswork quickly ossify as fact in the process of repetition), and their dispassionate analysis offsets the undue effects of charisma and naivety in determining the assignment of resources. As registers of the current and planned remedial work on species at risk, Red Data Books serve as a means of preventing needless repetition of particular studies; similarly, they introduce researchers previously unfamiliar with each other, and thus again help maintain complementarity of effort at minimal expense. Finally, they supply the factual basis for highly economical sitebased initiatives.

(e) They establish flagship species on the basis of need. Flagship animals have a distinct role to play in wildlife conservation, but their absorption of limited funds, to the literal loss of less familiar or attractive species, should be a calculated decision - albeit not one that boasts triage as its principle - rather than one based on ignorance of alternatives. Red Data Books make flagships of genuine cases and offer threatened species as indicators of wider diversity where no alternative mechanisms exist for its (rapid) measurement.

\section{(2) Comprehensiveness}

(a) They offer full coverage of major groupings. If the real extent of biodiversity on this planet is unknowable, then so is the real extent of what is being lost from it. It nevertheless remains vital to identify as many vanishing species as possible and to review, as thoroughly as possible, their conservation status and needs. The international Red Data Books are particularly well suited to this endeavour precisely because they take as their subjects entire classes of animals, or among invertebrates and plants (where too little is known across such broad spectra) those taxonomic groups that could be 
said to be representative of classes or their equivalents. By this means equal weight and due consideration are given to each and every species, irrespective of its perceived economic importance, ecological role or cuddle factor.

(b) They offer full coverage of major sources. Just as no species deserves to be marginalized because of its lack of human appeal, so no source of information relevant to its conservation deserves to be ignored. As McCoy (1995) observed, a full assessment of all the evidence, not just blind faith in the most recent findings, is essential to a proper understanding of the issues affecting a taxon's future. Red Data Books have precisely this remit.

(c) They create new depths of information. It is clearly important to assemble all the facts that are reasonably available: extinction is a serious matter and every small piece of knowledge may help avert it. It is not sufficient merely to list a species from a particular country or a region within it: it is necessary also to know its exact past and present range, its past and present numerical status, its seasonality, the current condition and protection status of its habitat, the adequacy of existing management, and so on. The compilation of rare or inaccessible material, such as museum specimen data and foreign-language theses, or the building of a review from a profusion of minor, dispersed sources, results in a significant depth of knowledge and renders the evidence as entire and intelligible as possible. It gives the future, or current, worker on the species the greatest chance to make the right decision, and helps prevent the wrong one being made through sheer ignorance.

(d) They are a primary source of data. While an account of a species obtains the equivalence of a scientific review paper, it may do much more. A thorough review of published sources need not contain new insights, but inevitably the assembling, analysis and reorganization of highly dispersed facts for the first time can result in important new perceptions on the status and needs of the species under scrutiny. Moreover, the addition of unpublished contri- butions from correspondents and museum specimen material greatly extends the originality of the text: real revelations can result. As such, a Red Data Book account becomes the central reference for a species, and the cornerstone for further documentation as well as for (further) action.

(e) They repatriate data. Many of the sources that provide perspective on and evidence for a species's former status - essential for an understanding of the degree and nature of its decline, and commonly for other relevant data such as its use of habitat - cannot be found in the countries to which the species is confined. Red Data Book accounts, properly researched, thus bring modern students of the species into contact with material otherwise commonly beyond their reach. This is one very positive reason why at least part of the work needs to remain an activity based in a 'centre of excellence', with access not only to literature but also to detailed maps and sources of expertise.

(f) They are the foundation for biodiversity databases. Threatened species information is a cornerstone of biodiversity database development. The post-1980 international Red Data Books report the degradation of ecosystems, unsustainable levels of exploitation, the plight of sympatric taxa and other factors related to the impoverishment of diversity. All such material can hugely enrich the data management systems currently being elaborated in the name of biodiversity. Moreover, the preparation of texts contributes significantly (through the accumulation of scientific papers, technical reports, contacts and general information on the status of key areas) to an inhouse hard-copy database on countries, areas, biomes, habitats, issues and management techniques, itself a significant investment for the future rapid acquisition and analysis of high-quality data.

(g) They create in-house levels of expertise (people as databases). Apart from the understanding of individual case-histories that accrues to them, 'compilers' inevitably achieve familiarity with the associated conservation issues, methods 
and practices, develop deep knowledge of the relevant literature, nations, institutions and personalities, and acquire an awareness of the appropriate manner in which to initiate or extend project-work on the species concerned (or biologically similar ones) or in the country where it occurs (or culturally similar ones).

\section{(3) Objectivity}

(a) They impose a global standard. Red Data Books provide rigorous analysis at the global level, using internationally agreed criteria (see IUCN, 1994), so that species are evaluated beyond their national significance. This cuts both ways: a species considered nationally at risk may prove globally secure, or a species considered nationally of low priority (often because of nationally scarcer species) may prove globally at risk (being highly threatened elsewhere), either way resulting in the opportunity to reshape policy and reallocate resources in the face of the nation's ultimate responsibilities.

(b) They are neutral and independent. Objectivity is an ideal rendered all the more exacting through the commitment to publish. It therefore requires the dispassionate but tactful representation and, if possible, resolution of ambiguities and contradictions that often arise within or between testimonies, or at least the disclosure of instances of divergent judgement or evidence. Independent review involves scrutinizing, perhaps for the first time, cases where a virtual monopoly on the conservation of a species exists. Even where the most comprehensive conservation programmes are under way, and when the drafting of text depends heavily on those with long-term commitments to and familiarity with a species, there remains great virtue in the neutral, external reporting of the situation, because this is to place the work in question under independent public scrutiny.

(c) They place the evidence in the public domain. It is of cardinal importance to make the accumulated evidence available, through publication and through the circulation of early drafts, to others. Openness to scrutiny and peer review is essential to the successful advocation of a course of action; it is the precondition of consensus because, like any aspect of science (and indeed like justice being seen to be done), it is essential to the confidence and trust of all parties. Publication also establishes a yardstick against which actions past and future can be measured, and which renders project work in some degree accountable; this in itself might in some cases be an incentive to responsible behaviour.

\section{(4) Motivation}

(a) They are democratic. The need to gather all data relevant to the saving of a species requires the consultation of all who have such information, irrespective of their official or professional status (although with due regard to their reliability). So long as their existence and addresses are discovered, people whose status, obscurity or isolation would normally bar them from contributing to international conservation programmes, and people who would not necessarily co-operate amongst themselves at the national level (even if only for geographic reasons, although all too often the obstacles lie elsewhere), can at least participate in and support this particular endeavour. Diversity of witness is a valuable attribute in establishing truth, but it is also a powerful precondition for successful action because it helps achieve consensus.

(b) They inspire participation. International Red Data Books remain in some quarters respected institutions, and in my experience many people regard the contribution of their data as a privilege or duty. Such motivation may be enhanced by the scrupulous attribution of information to its true source and the public acknowledgement of help, which not only establish the authority and responsibility of the participants but also retain and deepen their goodwill and sense of involvement. It is certainly mistaken to regard Red Data Books as preaching to the converted. In fact, it is often impossible to determine whether a species should be judged threatened until it is actually 
documented in full; sometimes it is only with the circulation of the draft text that witnesses are prompted to provide the clinching data.

\section{(c) They create the conditions for effective conser-} vation. Partly because of their prestige as official records, and partly because of their capacity to inspire and mobilize, Red Data Books pave the way for strong advocacy at local, national and international levels. By establishing (through broad consultation and accreditation) a sense of common ownership of the data and the decisions those data trigger, they encourage high levels of in-country commitment to and leadership on specific causes, in both governmental and non-governmental circles.

(d) They create networks. The exchange of data between 'compilers' and their networks inevitably includes material on the nature of the respective parties. From compilers emanate messages about the activities of their organizations, and in the network grows an understanding of those organizations and, often, a sense of loyalty to and identification with them. Thus people and institutions become a new resource in terms of data, help and involvement in issues (other than those simply concerning the species over which they were originally consulted). Red Data Books often prompt action among the very people first contacted for assistance, who welcome such international interest and are ready to devote time and energy to the further study and protection of particular species. Such people may form associations in the pursuit of this newly stimulated interest: these are the seeds of larger environmental movements, and an essential ingredient of all conservation progress in the long term.

(e) They shape and mobilize popular support. The idea of 'endangered species' is well entrenched in modern culture: the term has entered common English parlance and exercises a far stronger hold on the public imagination than 'biodiversity' ever can. Red Data Books are not produced for wide consumption but their mere existence allows them indirectly to mould and reinforce the current widespread interest in animals and plants. 'Biodiversity' may be the term that makes it acceptable for banks and government institutions to fund nature conservation in developing countries, but it is 'endangered species' that fuel public concern to see the deployment of such funding. Red Data Books inform the public which those species are.

(f) They educate. Not only do they serve as a general biological reference, an indicator of priorities and a source of previously unavailable data, all of which have strong educational values, Red Data Books also work to illuminate the theory and practice of threatened species documentation and prioritization. They expose those persons and institutions consulted for their input to the difficulties of judgement and the necessity of objective scrutiny. They expound the principles and processes involved. They internationalize consciousness.

(g) They become a sourcebook in conservation biology. All post- 1980 volumes provide a digest of information of general educational value in itself but also of major relevance in the modelling and development of programmes for other species. The bird volumes include detailed, condensed accounts of management histories where these exist, thereby illustrating many different types of conservation problem and their resolution. Such material has the capacity to alert present and prospective managers to the options and consequences they might not previously have considered concerning related species or situations with which they have to deal.

(h) They establish links with relevant disciplines. The exhaustive and detailed work required for the elaboration of a modern Red Data Book text inevitably entails much communication with experts and their institutions, and tends to generate new levels of interest in and goodwill for the applied science of conservation. Over time, connections are made that render the relations between conservation and the relevant institutions (universities, museums, 
zoological parks) and their respective disciplines or practices stronger and warmer, ultimately to the benefit of species and conservation.

\section{(5) Monitoring}

(a) They provide a baseline for the measurement of conservation progress. The detailed listing of proposed actions in Red Data Books is one very direct standard against which the level of intervention and management for a species can be measured over time. However, other detailed information in species accounts, on range, numbers and threats, also establishes the basis for future monitoring of success and failure in the conservation of individual species. Moreover, the species themselves can be used as monitors of endeavours to preserve sites and habitats and to confront and resolve specific issues, following the identification of these higher units of concern through Red Data Book analyses. No other type of documentation furnishes so complete a set of data against which species conservation progress can confidently be gauged.

\section{Conservation measures proposed}

Threatened species are not going to go away, not even by going extinct: there will always be more in the queue. Equally, there will always be public pressure to do something about them and substantial implications for nature conservation organizations that seek to ignore them.

The IUCN's answer has been to devolve responsibility for species documentation, analysis and indeed conservation to specialist groups. In the last 10 years or so, it has created as many such groups as possible, encouraging each to produce an Action Plan that identifies lower taxa at risk and prescribes appropriate management for them. In the absence of funds, this strategy has made sense: groups that can finance themselves to do such work, and perhaps even to undertake the highest priority projects that result from it, can at least take charge of some rationalized priorities in species conservation. Moreover, the IUCN has just recast its categories of threat, making them more exact, consistent and interpretable (IUCN, 1994), so that, in the absence of Red Data Book compilers, the many contributors to the IUCN's Action Plans have a standard evaluation procedure that allows their priority-setting exercises to be broadly comparable and equivalent. Meanwhile, the interest of the Captive (now Conservation) Breeding Specialist Group in interacting with some of these taxon groups has resulted in the development of CAMPs (Conservation Assessment Management Plans), in which the business of evaluation and priority-setting is condensed into a few days, with the intention of greatly accelerating the Action Plan process.

Welcome as these things may be, they are no full substitute for Red Data Books. To begin with, Action Plans and CAMPs provide for only a proportion of the species that are genuinely capable of evaluation: fewer than 100 of the 327 species treated in Threatened Birds of the Americas, for example, belong to families for which specialist groups exist. In addition, Action Plans have a necessarily limited capacity to mobilize public support, establish broad networks (beyond taxon-specific specialists), create in-house expertise, or deliver the great efficiency that results from the centralized pooling of detailed site and habitat data. (Without such pooling, dozens of sympatric species treated by the many different specialist groups require as many separate investigations to determine their status, and are still likely to be evaluated differently, depending on the thoroughness of individual compilers' inquiries, on the variation in data quality of the sources they consult, and on the interpretations they make of these data and of the IUCN criteria.)

Moreover, the lack of detailed distributional data in Action Plans reduces their utility for identifying areas of sympatric occurrence of threatened species, at precisely the time when this kind of user-friendly information, derived from integrated conservation databases, is not just desperately needed but also widely assumed (in the spheres conservationists most want to influence) to be readily available. It 
needs also to be recognized that CAMPs, in seeking to do in a few days with many participants what a Red Data Book does in many days with a few long-term participants (i.e. compilers), have only the advantage of time, while Red Data Books retain the advantage of truth, because the slower process of data accretion on a broad spectrum of taxa bestows the opportunity to check, consider and incorporate many more sources - particularly from the literature, and from those unable (or, worse, uninvited) to attend CAMPs - than the latter are able to tap before their course is run.

Finally, there is a significantly greater capacity in Red Data Books (first) to establish common ownership and national leadership on behalf of globally threatened species, and (second) to permit close monitoring of these species' status and conservation against a suite of data elements. These are genuine advantages that result in real conservation achievement, both indirectly through stronger, more certain advocacy of global priorities, and directly through practical intervention of many different types, derived from the immediate availability of high-resolution information and the general endorsement of the action which that information indicates is most appropriate.

The real answer has always been more data analysis not less, and the greater integration of the results of such work. Taxon-orientated Red Data Books are important, for all the reasons outlined above, but to optimize their value and impact they need constant reinterpretation through a second level of analysis. This should concentrate on outputs identifying key sites for threatened species and their major habitats, and the threats and issues that affect them. Much such analysis could simply be the reworking of data available in the taxon books; all of it would be targeted at those consumers of conservation data whose professional commitment to biodiversity requires very solid but very simple evidence to guide their decisions. Ironically, however, attempts to bring this second level into existence have only been made since the first was largely abandoned: the opportunity for mutually enhancing rigour and precision in priority- setting through their simultaneous activity and interplay has been missed.

The criteria of the new IUCN categories provide many different options depending on the type of information available. While some are stand-alones, others require multiple fulfilment. The system is certainly more accessible and open than the previous one, and part of its appeal clearly lies in the ability to make a more objective and defensible judgement of status based on relatively few and disparate items of data (see Mace, 1994). What seems inevitable, nevertheless, is that many decisions will require examination and debate; and then, even if agreement is widespread on the validity of the decision, many additional data will be needed to develop plans for the conservation of the species in question. In other words, public disclosure of the evidence is no less a requisite now than it ever was. By extension, Red Data Books are no less relevant today - in spite of the development of CAMPs and Action Plans, in part designed to fill the void - than they ever were.

Red Data Books are (seemingly) big and slow to grow and expensive to keep going; but so are rhinos, so are pandas, so are condors. It is the failure to appreciate their many virtues and values, so greatly outweighing their ostensible costs, that renders them vulnerable to extinction. Those who expect the discipline of biodiversity priority-setting to be satisfied by short-term on-site consultancies involving the scanning of forest-cover maps and protectedarea species inventories may well think of Red Data Books as dinosaurs that have had their day. Those who recognize the multitude of benefits that steadily accrue from focused and painstaking data assembly and analysis will appreciate Red Data Books as the unspectacular but indispensable root system from which true judgement and real conservation can grow.

\section{Acknowledgements}

I am very greatly indebted to M. J. Crosby, R. F. A. Grimmett, M. G. Kelsey, S. N. Stuart, D.C. Wege and S.M. Wells for their often extensive comments on various drafts of this article, and to two referees 
(U. Gärdenfors and J. A. Burton) for helpful further suggestions.

\section{References}

Bean, M.J. 1987. Legal experience and implications. In The Road to Extinction: Problems of Categorizing the Status of Taxa Threatened with Extinction (eds R. Fitter and M. Fitter), pp.39-43. International Union for Conservation of Nature and Natural Resources, Gland, Switzerland, and Cambridge, UK.

Bernardes, A.T., Machado, A.B.M. and Rylands, A.B. 1990. Fauna Brasileira Ameaçada de Extinção. Fundação Biodiversitas para a Conservação da Diversidade Biológica, Belo Horizonte.

Collar, N.J. 1994. Red Data Books, Action Plans, and the need for site-specific synthesis. Species, 21/22, 132-133.

Fitter, R. and Fitter, M. (eds). 1987. The Road to Extinction: Problems of Categorizing the Status of Taxa Threatened with Extinction. International Union for Conservation of Nature and Natural Resources, Gland, Switzerland, and Cambridge, UK.

IUCN Species Survival Commission. 1994. IUCN Red List Categories, as Approved by the 40th Meeting of the IUCN Council, Gland, Switzerland. International Union for Conservation of Nature and Natural Resources, Gland, Switzerland.

Long, A.J. 1995. The importance of tropical montane cloud forests for endemic and threatened birds. In Tropical Montane Cloud Forests (eds J. O. Juvik and F. N. Scatena), pp. 79-105. Springer-Verlag, New York.

Lovejoy, T.E. 1976. We must decide which species will go forever. Smithsonian, 7 (4), 52-59.

Mace, G.M. 1994. Classifying threatened species: means and ends. Phil. Trans. R. Soc. London, B 344, 91-97.

McCoy, E.D. 1995. The costs of ignorance. Conserv. Biol. 9, 473-474.

Myers, N. 1979. The Sinking Ark. Pergamon Press, Oxford.

Scott, P., Burton, J.A. and Fitter, R. 1987. Red Data Books: the historical background. In The Road to Extinction: Problems of Categorizing the Status of Taxa Threatened with Extinction (eds R. Fitter and M. Fitter), pp.1-5. International Union for Conservation of Nature and Natural Resources, Gland, Switzerland, and Cambridge, UK.

Wege, D.C. and Long, A.J. 1995. Key Areas for Threatened Birds in the Neotropics. BirdLife Conservation Series 5, BirdLife International, Cambridge, UK.

N. J. Collar, BirdLife International, Wellbrook Court, Girton Road, Cambridge CB3 ONA, UK. 